Joseph Siegel*

\title{
Comprehension in English Medium Instruction (EMI) lectures: On the impact of lecturer L2 English use
}

https://doi.org/10.1515/cercles-2020-2005

\begin{abstract}
The importance and amount of English as a Lingua Franca (ELF) usage and English Medium Instruction (EMI) lectures continue to increase on university campuses as universities worldwide seek to promote internationalization among both the student body and the faculty. While EMI has become a priority, the teaching and learning that occurs within this framework needs to be monitored for effectiveness and efficiency. Many of the teachers and students in these EMI courses do not share a common first language and likely have a first language other than English. Therefore, they are operating in EMI with varying levels of second language (L2) English ability, which can lead to low levels of student comprehension, learning and satisfaction unless the lecturer takes special care in their delivery of content. This paper explores the linguistic composition of EMI lectures in the Swedish context and reports survey findings of students' selfreported levels of comprehension related to lecture content and their lecturer's L2 English use. Three case studies are described and illustrate various linguistic factors that can contribute to or inhibit student comprehension in EMI lectures. Pedagogic implications are presented with the intention of supporting EMI lecturers and their students.
\end{abstract}

Keywords: English as a Lingua Franca (ELF), English Medium Instruction (EMI), lecture comprehension, case study, teaching in English

\section{Introduction}

Many lecturers and students in tertiary English Medium Instruction (EMI) courses do not share a common first language (L1) and likely have an L1 other than English. In addition, individuals in both groups inevitably have varying levels of second language (L2) English proficiency. In order to better understand the effects of EMI

*Corresponding author: Joseph Siegel, Örebro University, Örebro, Sweden; Stockholm University, Stockholm, Sweden. E-mail: joseph.siegel@english.su.se 
lecturers' English output on student comprehension, this study examined selfreported comprehension levels of students in three EMI courses taught by three L2 user lecturers at one Swedish university. After each lecture, students rated on a scale of 1-10 their levels of comprehension of the lecture content and the lecturer's English. Students also reported their native languages, which, when viewed in light of their reported comprehension levels, provides some insights into the complexities of EMI lecture delivery and comprehension.

This paper begins with a review of theoretical background and previous research relevant to EMI lectures and lecture comprehension. This overview covers macro- and micro-level choices lecturers make, obstacles L2 English users face in understanding EMI lectures, and delivery strategies of teachers. It provides a foundation for the present study, which adopted a case study framework and considers the relationship between self-reported comprehension of lecture content and lecturer English use. Three case studies of student-reported comprehension are shared to demonstrate various scenarios that can affect student comprehension in EMI lectures. Data collection and analysis methods are then presented, followed by a summary of findings, which leads to a discussion highlighting the importance of language use by EMI lecturers for crafting and delivering lectures in English in ways that facilitate rather than complicate listener uptake.

\section{Background}

Björkman (2018) emphasizes that all English as a Lingua Franca (ELF) usage is not equal and that each instance of EMI needs to be viewed within the sociolinguistic as well as educational contexts of each country. The project described in this paper involved EMI content courses at a university in central Sweden, a country where EMI courses have existed for more than 20 years (Kuteeva 2018) and have seen a recent dramatic increase (Forsberg 2018). Reasons for EMI in Sweden include implementing the Bologna process, increasing the number of exchange students, and promoting internationalization (Söderlundh 2014). The trend towards more EMI courses is common to other parts of Scandinavia as well and is prominent on an international scale. In a report that included 55 countries spanning Africa, Asia, Europe, and North and South America, approximately 75\% of public universities and $90 \%$ of private universities around the world allowed for EMI in their curricula (Dearden 2014), making this a topic of importance for tertiary education at a global level.

Since the individual lecturers and students who comprise EMI lectures often have a variety of L1s, and because their L2 English proficiencies can range widely, challenges exist for both. Lecturers are expected to deliver sophisticated and in- 
depth explanations of content through a language in which they may not be fully proficient. Students, on the other hand, are forced to utilize their L2 listening comprehension skills, which again, are likely developed to varying degrees. Furthermore, diverse undergraduate student groups will have varying amounts of background knowledge and experience related to the subject matter. While lecturers undoubtedly consider these perspectives in their teaching, variations in language proficiency and prior topic knowledge can lead to low levels of student comprehension and learning during EMI lectures. When lecturers are not attuned to the macro- and micro-level communicative decisions they make and the effects those choices can have on student comprehension, learning in EMI can prove strenuous. As pointed out by Querol-Julian and Crawford-Camiciottoli (2019), the proficiency levels of EMI lecturers and the EMI student body are often overlooked but crucial elements in terms of successful teaching and learning that are in need of further attention from educators and researchers alike.

Previous research has highlighted the ways in which content EMI lecturers often struggle to recognize their use of English as a pedagogic tool and their lack of appreciation for the range of English language proficiencies of the students who attend their lectures (e.g., Griffiths and Beretta 1991; Flowerdew and Miller 2000; see Querol-Julián and Crawford-Camiciottoli 2019 for a recent summary). In other words, teachers may assume that all students have the same L2 English proficiency and therefore aim their teaching and language selection to that level. One largescale study of countries where EMI is prominent revealed few pedagogic guidelines and a dearth of adequate linguistic training for would-be educators using EMI (Dearden 2014), indicating that attention to this area is warranted.

Murata (2018) underlines the "relatively unknown territory" (p. 1) related to ELF and EMI in educational contexts. In an effort to explore this gap, the present study focuses on the relationship between students' self-reported comprehension of lecture content and of the lecturer's English use through a case study design. The purpose of the project is to call attention to the complex linguistic nature of EMI environments and the myriad linguistic factors and combinations that can impact the degree of success lecturers have when teaching and students have when attending EMI lectures.

In tertiary education, the most consequential goal is knowledge transfer from lectures to learners (Lau et al. 2016). Since the vast majority of university courses are centered on the academic lecture, this particular genre of academic life is especially important as an object of study (Lynch 2011). While proponents of lectures may point to their potential efficiency and practicality for delivering information, lectures have also been decried for encouraging passive learning (Crawford-Camiciottoli and Querol-Julián 2016). According to research by Flowerdew and Miller (2000), the lecture is viewed as the most important part of 
university teaching, with one interviewee describing lectures as "the link between the body of knowledge and the students" (p. 121).

Various lecture styles have been identified and detailed through previous investigations. These include interactive and non-interactive varieties as well as the reading-aloud style (e.g., Morell 2004). However, interactive lecturing has become the prominent method of lecturing, which includes more dialogue between lecturer and audience and more reactive responses from the lecturer (e.g., Chang 2012). In recent years, the multimodal elements that combine in classrooms and lecture halls have been identified and scrutinized in detail. For example, Morell's, 2018 study of one EMI lecturer examined the use of speech, writing, gesture, space, and interactions. Conclusions from that study suggest that when a lecturer uses an L2, their multimodal competence becomes a pivotal factor in their educational effectiveness.

The widespread use of Powerpoint slides in university lectures has also impacted the quality of teaching and learning. James et al. (2006) found that both faculty and students recognize the advantages of Powerpoint for taking notes, performance on exams, emphasizing important information and holding student attention. While their results on the use of Powerpoint in business lectures were generally positive, lecturers often viewed the tool more favorably than students. In particular, aspects such as Powerpoint making learning more comfortable, leading to better note quality, and generating stronger retention of information were rated higher by faculty than students (James et al. 2006: p. 385). Roehling and TrentBrown (2011) found that Powerpoint is used more frequently with beginning level (i.e., undergraduate) courses than with those at higher levels (i.e., master's). The authors argue that this difference is due to the need for undergraduate students to grasp and digest key information in the field, whereas more advanced students need to develop critical thinking and discussion skills related to the subject content (Roehling and Trent-Brown 2011: p. 120).

The genre of the university lecture, however, is neither a uniform nor an objective domain, and the same applies to EMI lectures. In addition to the frequent use of Powerpoint and multimodal competencies, a typical lecture generally consists of a variety of different phases or segments arranged in one of several different ways. The selection and sequence of these segments likely depends on discipline, content, and individual lecturer style (the next sub-section expands on different parts of a lecture). In addition, lectures are "value-laden discourses" (Lee 2009) in which lecturers, through their choice of expressions, timing, sequencing, etc., evaluate and appraise the information they share with students. That is, the lecturer's personal views will, at least at times, be evident in their choices of expression, which can in turn, affect student comprehension and their interpretations of the value of the information. 
An extreme example comes from Griffiths and Beretta (1991), who analyzed English lectures given by the same teachers to three groups of students: (1) L1 English users; (2) high proficiency L2 English users; and (3) low proficiency L2 English users. Results showed that the teachers made no significant modifications to their spoken delivery, rate of speech, pausing patterns, and utterance construction based on the different groups to whom they spoke. In a study focused on physics lectures conducted in both English and Swedish, Airey and Linder (2006) found that the L1 Swedish students comprehended and participated less in the English versions of lectures. They also took fewer notes in the English compared to the Swedish lectures, demonstrating that the language in which a lecture is given impacts student confidence, engagement, and learning. More recent studies have focused on particular aspects of lecturer spoken production; for example, use of questions (Chang 2012), use of modifiers (Lau et al. 2016), and use of metaphors (Littlemore et al. 2011) during lectures.

\section{Macro and micro components of lectures}

Lectures consist of various organizational and linguistic elements that range from broad to specific structures. Previous research has identified and elaborated on overall lecture organizational styles, including the problem-solution pattern and a style that focuses on linking experimental data to theory and vice versa (e.g., Dudley-Evans 1994). Young (1994) outlined a set of macro-structures in lectures that can serve as a standard pattern of the lecture genre, which includes the following phases: announcing, discourse structuring, interaction, theory or content, examples, conclusion, and evaluation. Findings from analysis of a lecture corpus showed some consistency for these macro-phases among different disciplines, and Young (1994) suggests that L2 learners preparing for EMI be made explicitly aware of these common structures. It is important to note that these phases are not as clear-cut as a beginning, middle, end structure (such as that often found in academic essays), and that "each strand is interspersed with others, so that what emerges is a continual interweaving of threads of discourse which forms a macro-structure" (Young 1994: p. 172). In summarizing research on lectures, Crawford-Camiciottoli and Querol-Julián (2016) observe that many lectures do not have easily identifiable parts or sections and such fluidity can pose problems for L2 listeners.

Shifts between these phases are typically marked by topic shift markers, which "provide a structural basis for dividing up the lecture into smaller units" (Hansen 1994: p. 133). Use of such discourse markers has been shown to positively affect listeners' lecture comprehension (Crawford-Camiciottoli and Querol-Julián 2016; 
Rodgers and Webb 2016). Within each phase, lecturers make specific language choices that affect message delivery and therefore student interpretation and comprehension. At the smallest micro-component level is the phoneme, the individual sounds that the lecturer produces to form clusters, words, utterances, and so on. The speaker's accent, rate of speech, and pausing patterns are important micro-features that affect comprehension.

Recent research has moved away from the overall structural features of a lecture (i.e., macro-sections) to focus on specific micro-components of lecturer speech. Part of a study by Sheppard et al. 2015 concentrated on listener perception of lecturer output at the phoneme level (e.g., through reductions such as blending, elision, and deletion). At the utterance level, Chang (2012) investigated the teachers' questioning patterns in EMI lectures and suggests that students be aware of the "underlying logic of the use of questions" (p. 113) in order to maximize their understanding. Lau, Cousineau and Lin (2016) explored EMI lecturers' use of pragmatic force modifiers (e.g., actually, just, kind of) and found that student perceptions of lecturer output did not match the lecturers' intended pragmatic effect, leading to misunderstandings.

\subsection{Obstacles to student comprehension}

Based on the complex and interrelated combination of macro- and micro-components that comprise lectures, coupled with the fact that many students are listening in their L2, there is no shortage of obstacles to L2 student comprehension in EMI lectures. Among them are the high rate of speech, potentially unfamiliar accents, unknown cultural references, variation in lecturer style, inability to ask for clarification, new terms and concepts, and challenges in taking good notes. According to respondents in Bolton and Kuteeva's (2012) survey of EMI in Sweden, the English ability of lecturers can vary widely and can have a potentially negative impact, especially on exchange (i.e., non-Swedish) students. In the same report, concerns were raised about teachers with accents strong enough to affect comprehensibility (Bolton and Kuteeva 2012). Furthermore, students may struggle with understanding the relationship between verbal and nonverbal cues that combine to co-construct meaning within a range of academic listening situations (e.g., lectures, webinars and massive online open courses; Campoy-Cubillo and Querol-Julián 2015).

In past research, the onus was put on the student to improve their listening skills in order to cope with EMI lectures. Commentators stressed that teachers should suggest to students appropriate ways to listen to L2 lectures and that the problems in comprehension lay with the students rather than the lecturers' crafting 
and delivery of the lecture (e.g., Flowerdew 1994). Students in EMI lecturers have been described as "weak in following fast speech" and as "passive learners" (Flowerdew and Miller 2000: p. 130), descriptions that place blame on students and fail to recognize that lecturers can, for instance, adjust their rate of speech to accommodate students. While individual student ability and strategies are indeed crucial, some work has shifted responsibility, at least in part, from students to steps lecturers can take to incorporate L2 acquisition theory and acknowledge L2 English proficiency in order to improve student comprehension and learning.

\subsection{Lecturer delivery strategies}

Some lecturers may have no familiarity with language learning theory or be unaware of how their linguistic choices affect student aural comprehension (Flowerdew and Miller 1996). In order to support EMI lecturers who may be unfamiliar with language teaching and learning theories and/or unaware of their own English use, several strategies have been put forth to improve lecture delivery and student understanding. These strategies are likely to be of use to both L1 and L2 English users who lecture in EMI (Flowerdew and Miller 2000). To improve the situation related to L2 English use in ELF and EMI contexts, Björkman (2010) recommends both macro- and micro-level improvements. She argues that broad language policies should be clearly written in order to describe EMI contexts and the nature of the teaching and learning that occurs within them. At the institutional level, language training in ELF usage should be available to EMI lecturers. In addition, support for EMI students in terms of expectations and learning strategies would be beneficial (Björkman 2010).

Lecturers need to monitor, for example, their use of reductions (e.g., linking and blending phonemes, elision and deletion) as well as how they employ cultural and historical references, discourse markers and self-repairs (Sheppard et al. 2015). Among the strategies lecturers use, identified by Flowerdew and Miller (2000), were slowing the rate of speech and using simpler sentence structures. In other words, they observed that teachers tried to modify their output to match their language use to student proficiency levels, and both native and non-native English users employed these strategies.

In her investigation of ELF education in Sweden, Björkman (2010) examined the pragmatic strategies employed by lecturers. Findings from her analysis indicate that a lecturer's skillful use of pragmatic strategies is likely more important than their L2 English proficiency level. Several strategies and examples thereof are used to illustrate successful lecturing techniques, including "commenting on terms and concepts [...] labeling speech acts (i.e., by spelling out what it is the 
lecturer wants to do [and] signalling discourse markers)" (Björkman 2010: p. 81). The notion that pragmatic strategies may be more effective than high L2 proficiency can be viewed as encouraging for EMI lecturers, as a set of functional strategies may be more time-efficient to acquire and content-subject specific than attaining even higher proficiency.

Other solutions include making the individual lecturer's style clear to students, making transitional signals clear, giving students focusing questions at the beginning of a lecture, pausing regularly to avoid cognitive overload, and allowing for notetaking and collaboration (e.g., Flowerdew and Miller 2000; Rodgers and Webb 2016). Repetition of key points is an additional step EMI teachers can take (e.g., Flowerdew and Miller 1996), although the precise language used for signaling the repetitions and for the content of the repetitions themselves warrant specific attention from researchers, as simply repeating the same utterance that may have confused students in the first place would be unhelpful.

Visual aids, and software such as Powerpoint in particular, have become ubiquitous in higher education. Utilizing Powerpoint during lectures is largely viewed as advantageous for both lecturers and students, as the tool supports the organization of information, notetaking and holding student attention (e.g., Roehling and Trent-Brown 2011). However, the tool must be used with care to avoid negative effects such as overload of information or monotony. An offshoot strategy involving Powerpoint slides is evident when lecturers supply students with handouts of presentation slides and/or make slides available on online lesson management platforms (e.g., Moodle or Blackboard). While this effort may be supportive in some ways, it may also be demotivating in terms of student attention and attendance in class. Some research has found that faculty are concerned that making lecture material and slides available to students may negatively affect attendance (James et al. 2006). While lecturers have technological tools to help support student learning in and from lectures, these tools need to be used with care to maximize their effectiveness.

\subsection{Guiding research objectives}

In order to investigate the relationship between L2 English students' comprehension of lecture content and lecturer L2 English use in EMI lectures, this study focused on two guiding research objectives:

1. Describe the linguistic composition of EMI classrooms at one university in Sweden.

2. Describe the effects of EMI lecturers' spoken output on student comprehension of EMI lectures at one university in Sweden. 
As the research design focused on individual case studies, findings and discussion related to the research objectives cannot be generalized but instead are intended to raise lecturer and student awareness of the complexities and challenges involved for both parties in EMI.

\section{Methodology}

\subsection{Participants}

Three EMI lecturers at a university in central Sweden volunteered to participate in the project. All three cited interest in their students' reactions to their EMI lectures and an opportunity to consider their own L2 English use as motivations to participate. The lecturers taught in three different departments: sociology, artificial intelligence and computer graphics. All three speak English as an L2. Two were L1 Swedish users and the other had Italian as an L1. Based on the researcher's ELF interactions with the three lecturers, all of them were intelligible to an L1 English user.

Students who attended selected lectures for those courses completed online surveys at the conclusion of each lecture. Attendance at these small undergraduate lectures ranged from 9 to 15, and 128 total responses to the survey from 32 individual students were collected over 15 lectures. Student L2 English proficiency levels were not measured directly for this study. According to enrollment policies at the university where the study took place, to be eligible for an EMI course, students must have completed one of the following, per the university admissions office: (a) if the student comes from Sweden, they are required to pass two mandatory English courses at upper secondary school (with the expectation that their L2 English proficiency level is approximately B2); (b) if the student comes from outside of Sweden as an exchange student, the sending institution sets the L2 language proficiency requirements. Examples of the latter could include a strong score on IELTS or TOEFL or previous credits and/or graduation from another institution where English is used.

\subsection{Data collection instruments}

Students taking courses taught by these teachers completed a brief online survey designed by the author immediately following each lecture. The survey consisted of the following three questions:

1. What is your native language/mother tongue? 
2. On a scale of $1-10$, with 1 being $0 \%$ and 10 being $100 \%$, how much of the lecture content did you understand today?

3. On a scale of $1-10$, with 1 being $0 \%$ and 10 being $100 \%$, how much of the teacher's English did you understand today?

\subsection{Data collection and analysis procedures}

Students completed the online survey in the final 5 min of class time, immediately following that day's lecture. Data were collected via an online survey program and descriptive statistics were used to compare self-reported comprehension levels. Each lecturer was given a specific survey link for each of their lectures. This link was shared with students who attended the lectures and they were instructed to complete the survey as part of the project. Students were informed of the purpose of the project prior to the initial survey and completed the survey voluntarily. Only students in attendance that day completed the survey, and this was corroborated by checking lecturers' attendance lists with the number of online surveys completed for that lecture.

This study involved self-report data, which is vulnerable to various types of bias: self-deception bias (when respondents answer in accordance with how they would like to be viewed), prestige bias (responding in ways that will increase their standing in the eyes of teachers and/or researchers), and acquiescence bias (answering in ways they believe researchers want them to) (Wagner 2015). To offset potential bias, no personal information was gathered apart from one survey item about the student's L1.

A case study approach was applied to the data from each lecture. The data should be viewed for its value in capturing student perceptions of their comprehension at single points in time rather than as comprehensive and robust evidence of their comprehension. As such, each data set was examined as an isolated unit, with individuals with specific linguistic characteristics creating exclusive groups at different points in time.

\section{Findings}

In relation to the first guiding research objective related to linguistic composition of EMI lecture groups, a total of 12 native languages were identified when data from all three lecture groups are combined: Amharic, Croatian, English, French, German, Hungarian, Kurdish, Korean, Persian, Setswana, Swedish and Turkish. In response to the survey item about comprehension of lectures, students generally 
reported understanding between 70 and $90 \%$ of lecture content. For the item about comprehension of the lecturer's English, most responses were between 70 and $100 \%$. Taken as average overviews, these numbers suggest an appreciable amount of learning and comprehension. However, when the data are examined more closely at the individual lecture level, more disparity is evident, raising questions about who is learning, and what and how much is being learned.

The case studies presented below offer several insights into the complexities of teaching and learning in EMI and the need for careful consideration from several stakeholders, including students, lecturers, administrators, and policy makers. It is hoped that these case studies help inform stakeholders and stimulate similar examinations of the teaching and learning that is taking place as well as potential steps to improve the educational experience for students. As demonstrated by the situations described below, at least some students may be missing out on learning opportunities due to lack of congruence between their own L2 English comprehension and their lecturer's L2 English output.

\subsection{Case study 1}

The lecture included 15 students, 12 native Swedish users and 3 native German users, and the lecturer was an L1 Italian user. Since Swedish and English are both members of the Germanic branch of Indo-European languages, one might expect strong comprehension from all students, given the linguistic proximity of English to Swedish and German, as well as the generalized high English proficiency in those countries. Content comprehension scores, however, ranged from 5 to 10 (i.e., $50 \%$ of content to $100 \%$ total comprehension). Comprehension of the lecturer's English also ranged from 5 to 10, a range illustrated in Table 1.

Of particular interest in this example are two Swedish-speaking students. Student A reported 5/10 on content comprehension and 5/10 on English comprehension; thus, the latter response seems a logical reason as to why only $\sim 50 \%$ of the content was understood. However, Student B, also a native Swedish speaker, also reported $5 / 10$ on content comprehension but 10/10 on language comprehension. This disparity may be explained by Student A having more background knowledge of the topic. In addition, this finding demonstrates how students leave

Table 1: Responses to survey item 3 (comprehension of lecturer's English).

\begin{tabular}{llllllr}
\hline Scale of 1-10 & 5 & 6 & 7 & 8 & 9 & 10 \\
\hline No. of students & 2 & 2 & 1 & 2 & 4 & 4 \\
\hline
\end{tabular}


a lecture feeling they have understood roughly the same amount of content but at the same time understood vastly different amounts of language. One German student at the same lecture reported $9 / 10$ on content but only $6 / 10$ on language comprehension, also suggesting solid background and/or concept knowledge and/or effective visual aid use by the lecturer.

\subsection{Case study 2}

The teacher was a native Swedish user. The native languages of the nine students were: Swedish (4), Croatian (1), German (1), Hungarian (1), Korean (1) and Kurdish (1). As in Case study 1, the linguistic proximity of English to Swedish and German may have benefited those students. Having Croatian, with its Balto-Slavic roots, as an L1 did not disadvantage the lone L1 Croatian student, who reported 10/10 on both content and English comprehension. Two other students, the L1 Korean user and one of the L1 Swedish users, also registered 10/10 on comprehension of the teacher's English; thus, the Korean L1 user, despite having an L1 unrelated to English reported no trouble in comprehension.

However, the L1 Kurdish student reported struggling with scores of 1 and 2, respectively, as displayed in Tables 2 and 3, and perhaps partly explained by the distance between the student's L1 and English. Another notable low score was 4/10 on content comprehension by an L1 Swedish user, who understood $80 \%$ of the teacher's output, suggesting a lack of background and conceptual topic knowledge rather than major listening comprehension challenges. Overall, based on Case study 2, it seems that whether a student's L1 is closely related to or distant from English is less relevant than an individual's own L2 English proficiency, evidenced by the Croatian and Korean students who reported strong comprehension and the Swedish user who reported less than 50\% comprehension.

Table 2: Responses to survey item 2 (comprehension of lecture content).

\begin{tabular}{lllllllllll}
\hline Scale of 1-10 & $\mathbf{1}$ & $\mathbf{2}$ & $\mathbf{3}$ & $\mathbf{4}$ & $\mathbf{5}$ & $\mathbf{6}$ & $\mathbf{7}$ & $\mathbf{8}$ & $\mathbf{9}$ & $\mathbf{1 0}$ \\
\hline No. of students & 1 & - & - & 1 & - & - & 3 & 1 & 2 & 1 \\
\hline
\end{tabular}

Table 3: Responses to survey item 3 (comprehension of lecturer's English).

\begin{tabular}{lrllllllllr}
\hline Scale of 1-10 & 1 & 2 & 3 & 4 & 5 & 6 & 7 & 8 & 9 & 10 \\
\hline No. of students & - & 1 & - & - & - & - & 1 & 2 & 2 & 3 \\
\hline
\end{tabular}




\subsection{Case study 3}

The lecturer was a native Swedish user. Attending students reported the following mother tongues: Swedish (3), English (3), Turkish (2) and Setswana (1). Tables 4 and 5 show student responses regarding comprehension. The two students who reported 8/10 for lecturer's English were both native English users. This suggests that L1 English ability can actually be a detriment to understanding instruction when English is used as a lingua franca. All other students, including all three Swedish L1 users, both L1 Turkish users, 1 English L1 user, and the lone Setswana L1 user claim to have understood 100\% of the lecturer's English. The only two students to report less than 100\% comprehension of the lecturer's English (8/10) were both L1 English users, a finding that suggests that either (a) they were unaccustomed to use of ELF, or (b) the lecturer's output was aimed more at an ELF audience than at an L1 English user audience, or a combination of both a and b. It is worth emphasizing that none of the L2 English users reported any trouble understanding the lecturer's English and that everyone in this group (i.e., those reporting to understand $100 \%$ of the teacher's English) also understood $100 \%$ of the lecture content.

In summary, several issues relevant to the function of L2 English use by lecturers in EMI and its impact on student listening comprehension and learning were evident in these case studies. All stakeholders involved in EMI can incorporate findings such as these into their EMI teaching and learning contexts. One important point relates to the L1 of the lecturer and the proximity of a student's L1 to that of the lecturer. In other words, when a Swedish lecturer teaches in L2 English, students with Swedish as an L1 may have at least a slight advantage. Those students with L1 starkly different to Swedish may struggle, as is the case with the Kurdish student, although this was not always the case, as evidenced by the Korean L1 user. Individual student L2 proficiency, and listening ability in particular, should be of interest to lecturers so they can select relevant and effective

Table 4: Responses to survey item 2 (comprehension of lecture content).

\begin{tabular}{lllllllllll}
\hline Scale of 1-10 & 1 & 2 & 3 & 4 & 5 & 6 & 7 & 8 & 9 & 10 \\
\hline No. of students & - & - & - & - & - & - & 1 & 1 & 1 & 6 \\
\hline
\end{tabular}

Table 5: Responses to survey item 3 (comprehension of lecturer's English).

\begin{tabular}{|c|c|c|c|c|c|c|c|c|c|c|}
\hline Scale of $1-10$ & 1 & 2 & 3 & 4 & 5 & 6 & 7 & 8 & 9 & 10 \\
\hline No. of students & - & - & - & - & - & - & - & 2 & - & 7 \\
\hline
\end{tabular}


strategies, such as those summarized in the Background section, to support student learning. On the other hand, students may wish to attend to their lecturer's linguistic background and L2 English delivery and habits in order to make lecture comprehension easier. Furthermore, the use of technology (e.g., Powerpoint slide availability online) can make lectures less demanding, although these aspects were not directly examined in the present study.

Students and teachers who are accustomed to interacting with other L2 English users in ELF environments may find benefits from these experiences and transfer ELF skills to the EMI lecture context. Even L1 English users can struggle in EMI lectures, suggesting that L1-L2 or L2-L2 English communicative models may be preferable to those that focus on so-called "native speaker" norms. This notion suggests substantial influence for the future of ELF communication, as projections estimate that nearly two billion people worldwide use English as a second or additional language (Morrison 2016). When engaging in ELF communication with interlocutors or audiences who are not L1 English users, native users may need to, for example, avoid cultural references and idiomatic expressions, reduce their rate of speech, and articulate clearly rather than blending their speech in ways they might when speaking to another L1 English user (e.g., Morrison 2016). Such strategies can be added to the list offered in the Background section and would likely benefit both lecturers and their students.

\section{Discussion and implications}

The case study findings described above help address the research objectives related to linguistic composition of EMI groups and any effects of lecturer English use on students' self-reported comprehension levels. EMI lecture groups were typically comprised of students from several L1 backgrounds, although the majority in each lecture involved in this study were L1 Swedish users. Since the project was situated in Sweden, this is relatively unsurprising, and it seems reasonable to expect that the most common L1 in an EMI classroom will be the national/official language of the country in which the course is held.

Besides Swedish, the number of student L1s in the samples above ranged from 1 to 5. One lecture (case study 1) included only European languages (Swedish and German). Other lectures, especially case study 2, included a wide range of languages, including European and Asian languages. This diversity may present challenges for lecturers if they attempt to cater their output to a particular L1 background. When L1 English students are present, this is no guarantee that their comprehension of EMI content will be unconditional, and they may benefit from: (a) more experience in ELF interactions, (b) modifications from the lecturer, or both a and b. Furthermore, many of the L1s represented in these samples were used 
by only a single student (i.e., Setswana, Hungarian, Kurdish), meaning that the student would lack the opportunity to discuss course content, review notes and collaborate on course tasks with another student using the L1. Other students, Swedish, German and English L1 users in particular, would likely have that option.

While it may be interesting to consider whether English is an official or de facto official language of these students' home countries, several confounding factors disrupt such a perspective. First, the survey did not ask about country of origin. Secondly, some of the languages involved in this study, namely Kurdish and Setswana, are not associated with a single country in the same way that, for example, Swedish is linked to Sweden and German to Germany.

The descriptions of these EMI lectures can provide some insights about the EMI experience that may be valuable for both teachers and students, although the scope of this study was limited and class composition will be affected by several factors (geographic location, size of the university, academic discipline, etc.). Teachers can expect to encounter student groups with wide ranging L1s, although the national/official language of the country they are teaching in will likely be the most represented. While having some knowledge of this L1 would be useful for the teacher (and in fact, they might share the L1 with a majority of learners), it is important to recognize that students will have a range of L1s and that these L1s will differ greatly in their linguistic proximity to the common L1. Furthermore, the L2 English proficiency level of students will likely vary. Interestingly, during an inhouse workshop for EMI lecturers at the university where this study was conducted, all faculty in attendance indicated that they had no idea about their students' English proficiency levels or about university admissions policies related to enrollment in EMI courses. They also reported that they had no methods for ascertaining student English ability level early in their courses. Both of these observations are troubling and can be remedied through policies and awareness raising practices, as suggested by Björkman (2010).

From the student perspective, understanding the lecturer's L1, and its linguistic proximity to the individual student's L1, can be worthwhile, as this knowledge could contribute to student comprehension at the full range of levels, from pronunciation and accent up to lecture organization and delivery style typical of a certain culture (e.g., Flowerdew and Miller 2000). All of these observations are important for members of EMI lectures to consider in terms of listening comprehension (on the part of students) and the structuring and delivery of lecture content on the part of teachers.

Gaining insights such as these can help students, lecturers, administrators and researchers to understand the complex linguistic landscapes affecting the acts of teaching and learning in EMI. Since the genre of the university lecture inevitably involves two sides (i.e., a lecturer and a group of students), the chances for variability of and gaps in L2 proficiency increase. Complexity can 
certainly exist even when one of these sides includes L1 English users. If the lecturer has English as an L1 but speaks to a group of L2 English users as if they were L1 English students, there will likely be at least some misunderstandings by at least some of the students. When both the lecturer and the students are operating in L2 English and come from different cultural and linguistic backgrounds, along with potentially wide-ranging L2 English proficiency, finding an optimal way to ensure all students have equal opportunities and exposure to lecture content may prove strenuous. Add to the mix variations in background knowledge on the lecture topics and the EMI lecture hall becomes even more complicated.

With regard to the impact of lecturer L2 English ability on student comprehension, it is important to note that individual learner factors, the student's own listening ability, background knowledge, and motivation among them, often play significant roles in comprehension. While the lecturer's English use is not the sole factor, it remains one of the most tangible and one that students may identify most frequently when they elaborate on their ability to understand (or not) EMI lectures (e.g., Bolton and Kuteeva 2012). The case studies presented above indicate that the lecturer's English use has a strong impact on content comprehension, and that several students reported less than optimal lecture uptake. While lecturers whose L1 is not English may create an environment that facilitates understanding for those students familiar with ELF, L1 English students unaccustomed to such contexts may need additional support.

As a course progresses, students will become more familiar with a lecturer's individual English use and lecture style. They will inevitably adopt coping strategies for listening to and learning lecture content. Hopefully, teachers are attuned to student uptake levels (both related to content and language) and will also adjust pace and ambitions as appropriate. The following strategies can help EMI lecturers understand their own English use and the effects it may have on learning: record and transcribe a lecture or two, looking for aspects that may help or hinder student comprehension; elicit from students their L1s early on in the course and find out about common obstacles between those languages, the lecturer's L1 and English; learn about students' L2 English proficiencies and classifications (e.g., Common European Framework for References of Language, i.e., CEFR); find out about university entrance policies regarding L2 English proficiency; take regular low-stakes measures of lecture comprehension (e.g., rating scales, short quizzes, summarizing activities); monitor student facial expression and body language during lectures.

\section{Further research}

This paper has focused on case study descriptions of specific EMI lectures in an initial effort to highlight the intricacies of teaching and learning in such contexts. 
Therefore, more precise research measures are needed to expand on the issues highlighted thus far. For example, the survey included only simple 1-10 rating scales that do not provide insights as to specific factors that may have helped or hurt comprehension. Familiarity with a lecturer's accent over time should also be accounted for. Exploring the extent to which various macro- and micro-level aspects affect the L2 English comprehension of students would allow teachers to pinpoint where adjustments to lecture delivery might yield the most positive results. In addition, these initial self-report surveys about content understanding could be supplemented with measures of comprehension (e.g., multiple choice tests, written summary tasks, etc.), which would provide evidence to triangulate the self-report data. Studies that compare teacher expectations of learning with post-lecture student reports could also be useful in order to determine if students are learning what teachers expect them to learn during EMI.

\section{Conclusions}

The purpose of this paper has been to bring attention to the complex state of affairs in any EMI lecture, a complexity comprised of participants' L1s and L2 English proficiencies, along with students' prior topic knowledge. The present study has provided case study snapshots into three EMI lectures and has highlighted that EMI is not a uniform undertaking and that an understanding of the complex linguistic situations are needed to inform EMI teaching and learning as well as EAP preparation courses. These case studies emphasize that EMI lecturers and students are not equal in terms of L2 proficiency and that success and learning in EMI can range widely. This paper is meant as a first step in untangling and improving EMI instruction. Subsequent steps are necessary, such as proposing and implementing solutions from both student and lecturer standpoints. More studies are needed at the level of teaching and learning in EMI, particularly those that examine the triangle of complexity made up of the teacher's English output, the students' L2 English proficiency, and the lecture content. Individual learner factors undoubtedly affect the EMI comprehension process, among them L2 English listening ability, topical background knowledge and motivation), and these must be controlled for and factored into such research.

\section{References}

Airey, John \& Cedric Linder. 2006. Language and the experience of learning physics in Sweden. European Journal of Physics 27(3). 553-560. 
Björkman, Beyza. 2010. So you think you can ELF: English as a Lingua Franca as the Medium of Instruction. Hermes 23. 77-99.

Björkman, Beyza. 2018. English as a Lingua Franca in spoken genres in the international university: Introduction. Journal of English as a Lingua Franca 7(2). 225-228.

Bolton, Kingsley \& Maria Kuteeva. 2012. English as an academic language at a Swedish university: Parallel language use and the "threat" of English. Journal of Multilingual and Multicultural Development 33(5). 429-447.

Campoy-Cubillo, María Carmen \& Mercedes Querol-Julián. 2015. Assessing multimodal listening. In B. Crawford \& I. Fortanet-Gómez (eds.), Multimodal analysis in academic settings: From research to teaching, 193-212. London: Routledge.

Chang, Yu-Ying. 2012. The use of questions by professors in lectures given in English: Influences of disciplinary cultures. English for Specific Purposes 31. 103-116.

Crawford-Camiciottoli, Belinda \& Mercedes Querol-Julián. 2016. Lectures. In K. Hyland \& P. Shaw (eds.), The Routledge handbook of English for academic purposes 309-322. London: Routledge.

Dearden, Julie. 2014. English as a medium of instruction: A growing global phenomenon. British Council. Available at: https://www.britishcouncil.org/sites/default/files/e484_emi_-cover_option_3_final_web.pdf (accessed 7 March 2020).

Dudley-Evans, Tony. 1994. Variations in the discourse patterns favoured by different disciplines and their pedagogical implications. In J. Flowerdew \& L. Miller (eds.), Academic listening: Research perspectives, 146-158. Cambridge: Cambridge University Press.

Flowerdew, John. 1994. Research of relevance to second language lecture comprehension - an overview. In J. Flowerdew \& L. Miller (eds.), Academic listening: Research perspectives 7-29. Cambridge: Cambridge University Press.

Flowerdew, John \& Lindsey Miller. 1996. Lectures in a second language: Notes towards a cultural grammar. English for Specific Purposes 15(2). 121-140.

Flowerdew, John \& Lindsey Miller. 2000. Chinese lecturers' perceptions, problems and strategies in lecturing in English to Chinese-speaking students. RELC 31(1). 116-138.

Forsberg, Björn. 2018. Engelska allt vanligare som undervisningsspråk. [English as an increasingly common language of instruction]. Universitets Läraren, 8. 10-11.

Griffiths, Roger \& Alan Beretta. 1991. A controlled study of temporal variables in NS-NNS lectures. RELC 22(1). 1-19.

Hansen, Christa. 1994. Topic identification in lecture discourse. In J. Flowerdew \& L. Miller (eds.), Academic listening: Research perspectives, 131-145. Cambridge: Cambridge University Press.

James, Karen, Lisa Burke \& Holly Hutchins. 2006. Powerful or pointless? Faculty versus student perceptions of PowerPoint use in business education. Business Communication Quarterly 69(4). 374-396.

Kuteeva, Maria. 2018. Researching English-medium instruction at Swedish universities: Developments over the past decade. In K. Murata (ed.), English medium instruction from an English as a Lingua Franca perspective, 46-63. London: Routledge.

Lau, Ken, Jacob Cousineau \& Chia-Yen Lin. 2016. The use of modifiers in English-medium lectures by native speakers of Mandarin Chinese: A study of student perceptions. Journal of English for Academic Purposes 21. 110-120.

Lee, Joseph. 2009. Size matters: An exploratory comparison of small- and large-class university lecture introductions. English for Specific Purposes 28(1). 42-57.

Littlemore, Jeannette, Phyllis Trautman Chen, Almut Koester \& John Barnden. 2011. Difficulties in metaphor comprehension faced by international students whose first language is not English. Applied Linguistics 32(4). 1-23. 
Lynch, Tony. 2011. Academic listening in the 21st century: Reviewing a decade of research. Journal of English for Academic Purposes 10. 79-88.

Morell, Teresa. 2004. Interactive lecture discourse for university EFL students. English for Specific Purposes 23(3). 325-338.

Morell, Teresa. 2018. Multimodal competence and effective interactive lecturing. System 77 , 70-79.

Morrison, Lennox. 2016. You need to go back to school to relearn English. British Broadcasting Company. Available at: https://www.bbc.com/worklife/article/20161215-you-need-to-goback-to-school-to relearn-english (accessed 4 January 2020).

Murata, Kumiko. 2018. Exploring EMI in higher education from an ELF perspective: Introduction. In K. Murata (ed.), English Medium Instruction from an English as a Lingua Franca perspective, 1-12. London: Routledge.

Querol-Julián, Mercedes \& Belinda Crawford-Camiciottoli. 2019. The impact of online technologies and English Medium Instruction on university lectures in international learning contexts: A systematic review. ESP Today 7(1). 2-23.

Rodgers, Michael \& Stuart Webb. 2016. Listening to lectures. In K. Hyland \& P. Shaw (eds.), The Routledge handbook of English for academic purposes, 165-176. London: Routledge.

Roehling, Patricia \& Sonja Trent-Brown. 2011. Differential use and benefits of PowerPoint in upper level versus lower level courses. Technology, Pedagogy and Education 20(1). 113-124.

Sheppard, Beth, Jennifer Rice, Korey Rice, Brendan DeCoster, Rachel Dummond-Sardell, Nate Soelberg, 2015. Re-evaluating the speaking and listening demands of university classes for novice international students. ORTESOL Journal 32. 1-12. https://ortesol.wildapricot.org/ Journal2015. (Accessed 10 June 2020).

Söderlundh, Hedda. 2014. Zooming in on language practices in Swedish higher education. In Anna Kristina Hultgren, Frans Gregersen \& Jacob Thøgersen (eds). English in Nordic Universities: Ideologies and practices, 111-126. Amsterdam: John Benjamins.

Wagner, Elvis. 2015. Survey research. In B. Paltridge \& A. Phakiti (eds.), Research methods in applied linguistics, 83-100. London: Bloomsbury.

Young, Lynne. 1994. University lectures-macro-structure and micro-features. In John Flowerdew \& Lindsey Miller (eds.), Academic listening: Research perspectives, 159-176. Cambridge: Cambridge University Press.

\title{
Bionote
}

\author{
Joseph Siegel \\ Stockholm University, Stockholm, Sweden \\ Örebro University, Örebro, Sweden
}

Joseph Siegel is associate professor (docent) in English at Stockholm and Örebro Universities in Sweden, where he teaches TESOL methodology, linguistics, and applied linguistic research methods courses. He holds a PhD in Applied Linguistics from Aston University and an MA (TESL/ TEFL) from the University of Birmingham. His recent publications are on the topics of action research, notetaking, listening pedagogy, and pragmatic instruction. 